\title{
A Propensity Score Matched Comparison of Brand and Biosimilar Basal Insulin in Non-Critical Hospitalized Patients with Type 2 Diabetes Mellitus
}

\author{
Xia Hu • Lei Zhang · Chao Dong · Yanhu Dong · Jikang Jiang • \\ Weiguo Gao
}

Received: January 25, 2019 / Published online: March 21, 2019

(C) The Author(s) 2019

\begin{abstract}
Introduction: Comparisons between brand and biosimilar basal insulin in hospitalized patients are lacking. We aimed to compare the efficacy and safety of brand insulin glargine vs. biosimilar insulin glargine in non-critical hospitalized patients with type 2 diabetes mellitus (T2DM). Methods: This retrospective study was conducted using the electronic medical records of 194,006 patients at the Qingdao Endocrine and Diabetes Hospital between January 2006 and December 2017. A total of 476 patients diagnosed with T2DM, hospitalized, and treated with subcutaneous insulin glargine were included. After propensity score matching (1:3), patients who received biosimilar insulin glargine (Basalin) $(n=34)$ were compared to a matched group of patients who received brand insulin glargine (Lantus) $(n=101)$. Outcome measures were changes in fasting blood glucose (FBG), the incidence of hypoglycemia, and insulin dose.
\end{abstract}

Enhanced Digital Features To view enhanced digital features for this article go to https://doi.org/10.6084/ m9.figshare.7771049.

X. Hu · L. Zhang · C. Dong · Y. Dong · J. Jiang · W. Gao (ه)

Qingdao Endocrine and Diabetes Hospital, Fuzhou

Road 81, Qingdao 266071, China

e-mail: weiguo.gao@diabeteschina.com
Results: Compared to patients who received Basalin, patients who received Lantus achieved more reduction in FBG during insulin treatment $(-1.24 \mathrm{mmol} / \mathrm{L}$ vs. $-2.20 \mathrm{mmol} / \mathrm{L} ; p=0.04)$ and had a lower mean FBG at the end of treatment $(8.20 \mathrm{mmol} / \mathrm{L}$ vs. $7.26 \mathrm{mmol} / \mathrm{L} ; p=0.12)$. Patients in Basalin and Lantus groups had a comparable mean daily dose of basal insulin at initiation ( 0.19 vs. $0.18 \mathrm{IU} / \mathrm{kg} ; p=0.30)$ and end of treatment $(0.21$ vs. $0.21 \mathrm{IU} / \mathrm{kg} ; p=0.99)$, and a similar duration of basal insulin treatment (16.4 vs. 15.3 days; $p=0.74$ ). Hypoglycemia was infrequent in both Basalin and Lantus treatment (one vs. four patients, respectively; $p=1.00)$ and no severe hypoglycemic events were reported.

Conclusion: In a non-critical hospital setting, subcutaneous treatment with Lantus brought significant FBG improvement without increased hypoglycemic risk.

Keywords: Biosimilar; Insulin glargine; Type 2 diabetes mellitus

$\begin{array}{ll}\text { Abbreviations } \\ \text { BG } & \text { Blood glucose } \\ \text { BMI } & \text { Body mass index } \\ \text { FPG } & \text { Fasting plasma glucose } \\ \text { IU } & \text { International units } \\ \text { T2DM } & \text { Type } 2 \text { diabetes mellitus }\end{array}$




\section{INTRODUCTION}

Patients with diabetes are at high risk of hospitalization, which is three-fold greater than patients without diabetes [1]. It is reported that around $30 \%$ of patients with type 2 diabetes mellitus (T2DM) had been hospitalized in 1 year [2]. However, reasons for hospitalization are diverse, including chronic complications of diabetes, infection, cardiovascular disease, hypoglycemia, etc. $[3,4]$. In such patients, aside from disease leading to hospitalization, diabetes management is important. Uncontrolled hyperglycemia or hypoglycemia is associated with poor hospital outcomes including prolonged hospital stay, increased ICU admission rate, even increased mortality rate [5-8]. As a result, the goal of diabetes management in hospitalized patients is to minimize the impact of hyperglycemia on the disease which leads to hospitalization, prevent hypoglycemia, and ensure a smooth transition to outpatient treatment.

Basal insulin, NPH or insulin glargine, is the most commonly used regimen in diabetes management in hospital, together with mealtime insulin or oral antihyperglycemic drugs. Compared to NPH-based regimen, insulin glargine-based regimen is associated with lower rate of symptomatic hypoglycemia, nocturnal hypoglycemia, and severe hypoglycemia $[9,10]$. Therefore, insulin glargine is more popular in the management of diabetes among inpatients mainly due to the reduction of hypoglycemia events and related hospital costs.

Two versions of insulin glargine are available in China at present: the brand insulin glargine (Lantus, Sanofi, Germany) and the biosimilar insulin glargine (Basalin, Gan \& Lee, China). Both versions of insulin glargine have been available since 2005 in China, and gradually replaced NPH usage in outpatients and inpatients in the past decade [11]. The biosimilar insulin glargine has a lower price than the brand insulin glargine. But direct comparisons of efficacy and safety between the two versions of insulin glargine are limited and controversial. A pharmacologic study has shown bioequivalence of Lantus and Basalin in Chinese healthy volunteers [12]. But in our previously conducted retrospective analysis, switching from the biosimilar insulin glargine to the brand insulin glargine was associated with further reductions in blood glucose, without dose increasing [13].

To compare the efficacy and safety of treatment with brand and biosimilar basal insulin, we did a propensity score matched, retrospective analysis in non-critical hospitalized patients with T2DM, because these patients required high-quality glycemic control, which meant achieving and maintaining normoglycemia (FBG 6.1-7.8 mmol/L) without hypoglycemia.

\section{METHODS}

\section{Data Source}

This was a retrospective study using the electronic medical records (EMRs) of patients hospitalized at the Qingdao Endocrine and Diabetes Hospital (the Hospital) in China, from January 2006 to December 2017. Detailed information of the hospital and patients was previously published [14]. In general, the hospital is a public, non-profit, tertiary hospital specializing in the management of diabetes. Patients were admitted to the hospital mainly as a result of uncontrolled hyperglycemia, including persistent hyperglycemia, newly diagnosed diabetic patients with $\mathrm{HbA} 1 \mathrm{c}>9 \%$ or FPG $>11 \mathrm{mmol} / \mathrm{L}$, diabetic ketoacidosis, diabetic hyperosmolality, etc., and worsening of chronic complication, including coronary heart disease, diabetic neuropathy, diabetic retinopathy, etc. Non-critical patients defined as patients treated with subcutaneous injection of basal insulin, together with or without mealtime insulin or oral antihyperglycemic drugs, aimed to achieve normoglycemia (FBG 6.1-$7.8 \mathrm{mmol} / \mathrm{L}$ ) without hypoglycemia. Brand selection of basal insulin (Lantus or Basalin) was based on patients insurance coverage, patients affordability, and patients' insulin accessibility after discharge.

The data selection process for the current study is summarized in Fig. 1. EMRs were initially searched using the keywords "Lantus," 


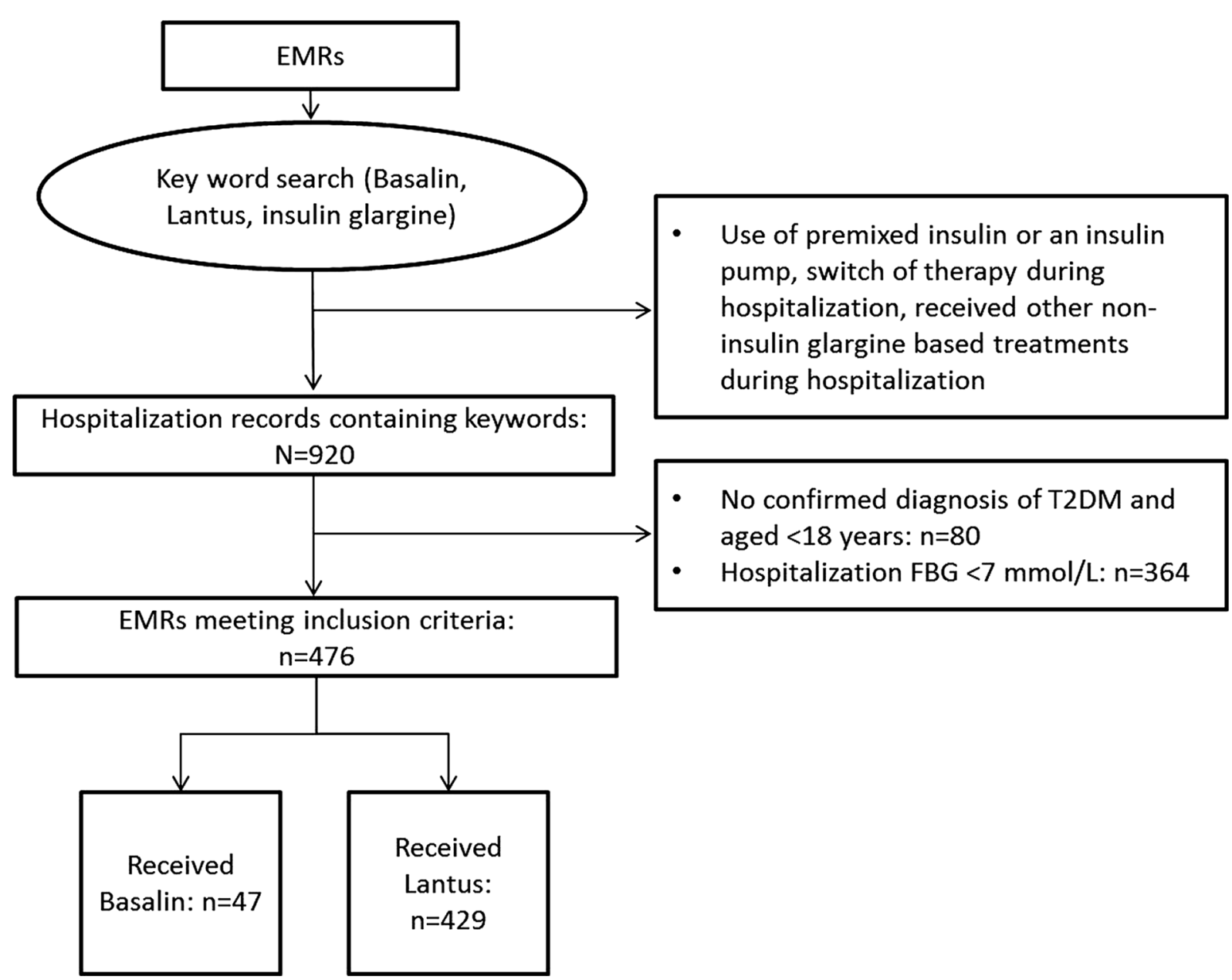

Fig. 1 Data selection pathway. EMR electronic medical record, $F B G$ fasting blood glucose, $T 2 D M$ type 2 diabetes mellitus

"Basalin," or "insulin glargine" to identify patients with recorded use of insulin glargine during hospitalization. The following exclusion criteria were then applied: treatment with basal insulin other than insulin glargine, switching insulin therapy during hospitalization; critically ill patients (acute diabetic complications, diabetic coma caused by hypoglycemia, diabetes comorbid with infection, severe renal or hepatic impairment), age $<18$ years; no confirmed T2DM diagnosis; or adequate glycemic control (FBG $\leq 7 \mathrm{mmol} / \mathrm{L}$ ) at hospital admission.

The first day of subcutaneous injection of basal insulin was defined as the start of treatment (baseline), while the day of discharge was defined as the end of treatment. Hypoglycemia was defined as any recorded incidence of blood glucose $(\mathrm{BG}) \leq 3.9 \mathrm{mmol} / \mathrm{L}$, and severe hypoglycemia was defined as requiring assistance from others to administrate carbohydrates, glucagon, or other resuscitative actions, with or without $\mathrm{BG} \leq 3.0 \mathrm{mmol} / \mathrm{L}$.

The study was approved by the hospital ethical committee and all procedures were in accordance with the 1964 Helsinki declaration and its later amendments or comparable ethical standards. Informed consent was obtained from all individual participants included in the study.

\section{Definition of Clinical Outcomes}

The efficacy outcomes of this analysis were change in fasting blood glucose (FBG) from start to end of basal insulin treatment, final FBG 
value, change in daily glucose profile (measured at seven points of glucose, namely fasting, at time of each meal and $2 \mathrm{~h}$ post each meal, and at bedtime) from start to end of basal insulin treatment, dose of basal insulin at treatment end, duration of basal insulin treatment, and duration of hospitalization.

The safety outcome of this analysis was the incidence of hypoglycemia.

\section{Statistical Methods}

Data were analyzed and reported using SAS software (v.9.4). Propensity score matching was conducted using Proc PSMATCH in SAS software (v.9.4). Each propensity score included the following explanatory variables at baseline of treatment which could potentially be related to any confounding effect on BG values

Table 1 Patient baseline characteristics

\begin{tabular}{|c|c|c|c|c|c|c|}
\hline & \multicolumn{3}{|l|}{ Pre-matching } & \multicolumn{3}{|c|}{ Post-matching 1:3 } \\
\hline & $\begin{array}{l}\text { Basalin, } \\
n=47\end{array}$ & $\begin{array}{l}\text { Lantus, } \\
n=429\end{array}$ & $p$ & $\begin{array}{l}\text { Basalin, } \\
n=34\end{array}$ & $\begin{array}{l}\text { Lantus, } \\
n=101\end{array}$ & $p$ \\
\hline Age, years & $61.53(10.37)$ & $62.99(12.08)$ & 0.43 & $61.91(10.84)$ & $61.57(11.96)$ & 0.88 \\
\hline Males, $n(\%)$ & $19(40.4)$ & $239(55.7)$ & 0.06 & $11(32.4)$ & $37(36.6)$ & 0.68 \\
\hline BMI, $\left(\mathrm{kg} / \mathrm{m}^{2}\right)$ & $27.12(3.86)$ & $27.05(15.90)$ & 0.94 & $27.25(3.39)$ & $29.32(32.12)$ & 0.52 \\
\hline Diabetes duration, years & $8.11(4.98)$ & $11.30(6.67)$ & $<0.01$ & $8.53(5.12)$ & $8.22(4.75)$ & 0.75 \\
\hline \multicolumn{7}{|l|}{ Treatment regimen } \\
\hline Basal insulin $+\mathrm{OAD}(\mathrm{s})$ & $27(57.4)$ & $279(65.0)$ & 0.34 & $20(58.8)$ & $60(59.4)$ & 1.00 \\
\hline Basal insulin + prandial insulin & $20(42.6)$ & $150(35.0)$ & & $14(41.2)$ & $41(40.6)$ & \\
\hline \multicolumn{7}{|l|}{ Number of OADs } \\
\hline 0 & $20(42.6)$ & $150(35.0)$ & 0.28 & $14(41.2)$ & $41(40.6)$ & 0.51 \\
\hline 1 & $6(12.8)$ & $64(14.9)$ & & $5(14.7)$ & $11(10.9)$ & \\
\hline 2 & $7(14.9)$ & $122(28.4)$ & & $4(11.8)$ & $25(24.8)$ & \\
\hline 3 & $10(21.3)$ & $69(16.1)$ & & $8(23.5)$ & $14(13.9)$ & \\
\hline 4 & $4(8.5)$ & $22(5.1)$ & & $3(8.8)$ & $9(8.9)$ & \\
\hline 5 & 0 & $2(0.5)$ & & 0 & $1(1.0)$ & \\
\hline $\begin{array}{l}\text { History of cardiovascular disease, } \\
n(\%)\end{array}$ & $19(40.4)$ & $207(48.3)$ & 0.36 & $15(44.1)$ & $48(47.5)$ & 0.84 \\
\hline History of smoking, $n(\%)$ & $14(29.8)$ & $165(38.5)$ & 0.27 & $7(20.6)$ & $29(28.7)$ & 0.50 \\
\hline $\begin{array}{l}\text { History of diabetic complications, } \\
n(\%)\end{array}$ & $43(91.5)$ & $416(97.0)$ & 0.08 & $31(91.2)$ & $98(97.0)$ & 0.17 \\
\hline $\mathrm{HbAlc}$ at admission, (\%) & $8.37(1.91)$ & $7.98(1.65)$ & 0.19 & $8.31(1.89)$ & $8.32(1.98)$ & 0.97 \\
\hline $\mathrm{FBG},(\mathrm{mmol} / \mathrm{L})$ & $9.64(2.72)$ & $9.14(1.96)$ & 0.23 & $9.44(2.37)$ & $9.46(2.25)$ & 0.96 \\
\hline $\begin{array}{l}\text { Starting dose of basal insulin, } \\
\text { (IU/kg) }\end{array}$ & $0.19(0.07)$ & $0.19(0.07)$ & 0.72 & $0.20(0.06)$ & $0.19(0.07)$ & 0.30 \\
\hline
\end{tabular}

$B M I$ body mass index, $F B G$ fasting blood glucose

$p$ values calculated using a Student's $t$ test for continuous variables and Chi-square test for categorical variables 
independent of basal insulin treatments: age, gender, BMI, diabetes duration, treatment regimen, number of oral antidiabetic drugs (OADs), history of cardiovascular disease, history of smoking, history of diabetic complications, HbA1c and FBG at admission, starting dose of basal insulin (Table 1). Matching was conducted to minimize selection biases which might confound comparisons between basal insulin treatments. Matched explanatory variables in the current logistic model included gender, age, HbA1c and FBG at baseline, diabetes duration. The difference in the logit of the propensity score (LPS) was selected as the statistic for matching subjects in two treatment groups. All available observations were selected and a greedy nearest neighbor matching algorithm matched the Basalin to the Lantus cohort by 1:3 without replacement. Matching used a default caliper width of 0.25 times the standard deviation of the estimated LPSs. A sensitivity analysis was also conducted using 1:1 and 1:2 matching, individually. Mean change in FBG from baseline was compared between the two treatment groups before and after matching, as well as mean changes in seven-point BG profiles.

Continuous variables are presented as mean (standard deviation, SD), and discrete variables are summarized as frequency and percentage. Pre- and post-matching, treatment differences between the Basalin and Lantus groups were assessed using either Student's $t$ test or Chi- square test, depending on each variables' properties. A $p$ value less than 0.05 was considered statistically significant. All analyses were conducted using SAS software (version 9.4).

\section{RESULTS}

\section{Patient Characteristics}

A total of 47 patients treated with Basalin and 429 treated with Lantus met the study criteria and were eligible for matching. There were remarkable differences between these unmatched treatment groups at baseline in terms of their mean duration of diabetes (8.1 months vs. 11.3 months; $p<0.01$ ) and the proportion of male patients $(40.4 \%$ vs. $55.7 \% ; p=0.06)$ (Table 1). After matching, differences in sevenpoint BG values were minimized between two treatment groups at baseline (Table 2, Fig. 2a).

After propensity score matching, the 1:3 matched cohorts included 34 patients who had received Basalin and 101 patients who received Lantus (Table 1). As expected, there were no statistically significant differences between the two groups at the post-matching baseline.

\section{Changes in Blood Glucose}

Post-matching, patients who received Lantus achieved a significantly greater mean reduction

Table 2 Baseline seven-point blood glucose

\begin{tabular}{lccccccc}
\hline & Pre-matching & & & Post-matching \\
& Basalin, $\boldsymbol{n}=\mathbf{4 7}$ & Lantus, $\boldsymbol{n}=\mathbf{4 2 9}$ & $\boldsymbol{p}$ & & Basalin, $\boldsymbol{n}=\mathbf{3 4}$ & Lantus, $\boldsymbol{n}=\mathbf{1 0 1}$ & $\boldsymbol{p}$ \\
\hline FBG & $9.64(2.72)$ & $9.14(1.96)$ & 0.23 & $9.44(2.37)$ & $9.46(2.25)$ & 0.96 \\
Post-breakfast BG & $12.24(3.48)$ & $11.72(3.34)$ & 0.33 & $12.18(2.74)$ & $12.21(3.85)$ & 0.95 \\
Pre-lunch BG & $10.51(4.36)$ & $10.13(3.14)$ & 0.61 & $9.84(3.56)$ & $10.14(3.36)$ & 0.69 \\
Post-lunch BG & $11.62(3.69)$ & $11.07(3.37)$ & 0.30 & $11.26(3.08)$ & $10.90(3.70)$ & 0.62 \\
Pre-dinner BG & $9.55(3.77)$ & $9.42(3.20)$ & 0.81 & $9.31(3.36)$ & $9.42(3.25)$ & 0.88 \\
Post-dinner BG & $11.24(3.54)$ & $11.24(3.26)$ & 1.00 & $10.97(3.30)$ & $10.99(3.44)$ & 0.98 \\
Pre-bedtime BG & $10.29(3.54)$ & $10.10(3.21)$ & 0.72 & $10.06(3.40)$ & $10.44(3.30)$ & 0.59 \\
\hline
\end{tabular}

$B M I$ body mass index, FPG fasting plasma glucose

$p$ values calculated using a Student's $t$ test 

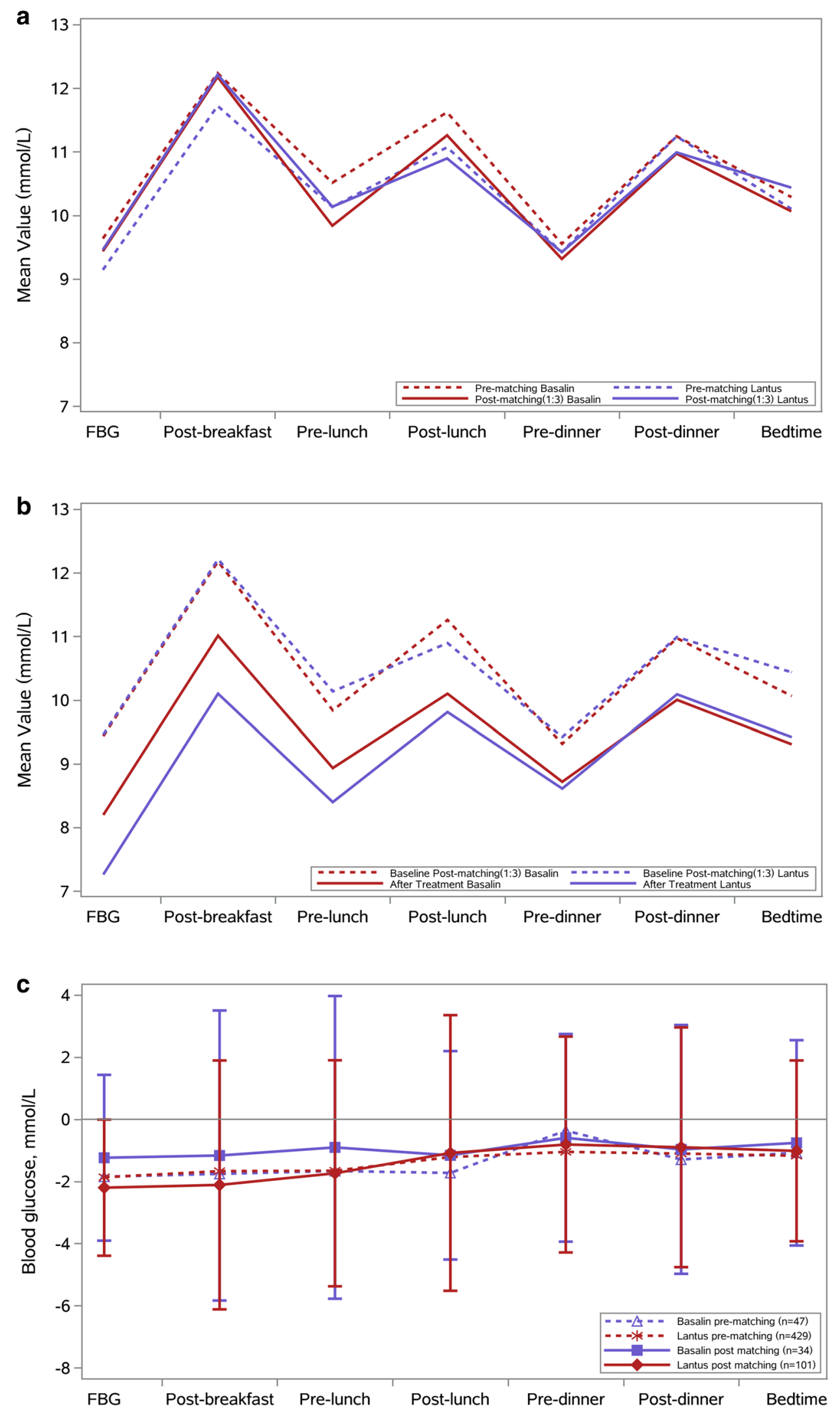
4Fig. 2 Seven-point blood glucose measurements a at baseline before and after 1:3 propensity score matching, b at baseline and after treatment after 1:3 propensity score matching, and c change in blood glucose measurements from hospitalization to end of treatment, for patients with T2DM treated with Basalin or Lantus. Dotted lines represent patients who received Basalin, solid lines represent patients who received Lantus

in FBG from baseline to end of treatment versus those who received Basalin $(-2.20 \mathrm{mmol} / \mathrm{L}$ vs. $-1.24 \mathrm{mmol} / \mathrm{L} ; p=0.04$ ) (Fig. 3). The mean FBG value at the end of treatment was numerically lower for patients treated with Lantus versus those treated with Basalin $(7.26 \mathrm{mmol} / \mathrm{L}$ vs. $8.20 \mathrm{mmol} / \mathrm{L} ; p=0.12$ ).

Changes in mean seven-point BG profiles between baseline and end of treatment were observed in both the Basalin and Lantus treatment groups (Fig. 2b). Patients treated with Lantus showed a trend towards lower mean post-breakfast and pre-lunch BG levels compared with those receiving Basalin, although these differences did not reach statistical significance (Table 2, Fig. 2c).

\section{Insulin Dose and Duration of Treatment}

There was no significant difference in the daily dose of basal insulin between the Basalin and
Lantus groups at baseline (0.19 vs. $0.18 \mathrm{IU} / \mathrm{kg}$; $p=0.30)$ or end of treatment (0.21 vs. $0.21 \mathrm{IU} /$ $\mathrm{kg} ; p=0.99)$. Similarly, the duration of basal insulin treatment (16.4 vs. 15.3 days; $p=0.74$ ) and length of hospitalization (19.5 vs. 17.7 days; $p=0.60$ ) were comparable between the matched groups.

\section{Safety}

The incidence of hypoglycemia was low and comparable between patients who received Basalin and Lantus; hypoglycemia occurred in one versus four patients, respectively $(p=1.00)$. No patient in either group experienced a severe hypoglycemic event and no other adverse events were recorded.

\section{Sensitivity Analysis}

A sensitivity analysis comparing outcomes for matched cohorts of Basalin/Lantus patient ratios of $1: 1$ and $1: 2$ showed similar results as for the main 1:3 analysis (Table 3 ).
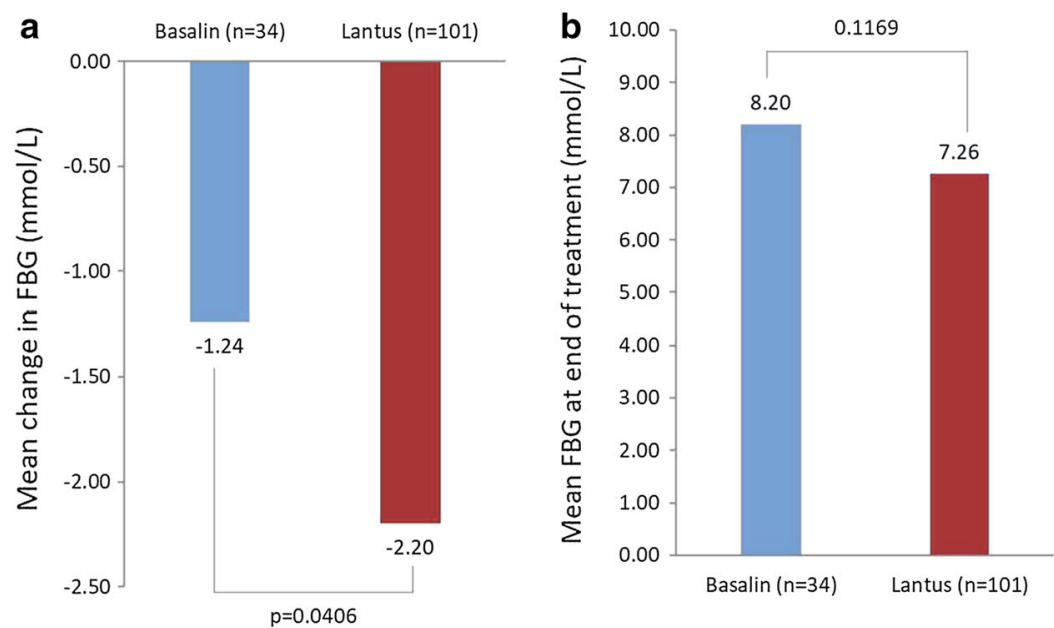

\section{DISCUSSION}

To our knowledge, this study is the first comparison of the efficacy of brand and biosimilar
Fig. 3 a Mean change in FBG from baseline to end of treatment, $\mathbf{b}$ mean FBG at end of treatment, and $\mathbf{c}$ mean insulin dose at end of treatment, for patients with T2DM

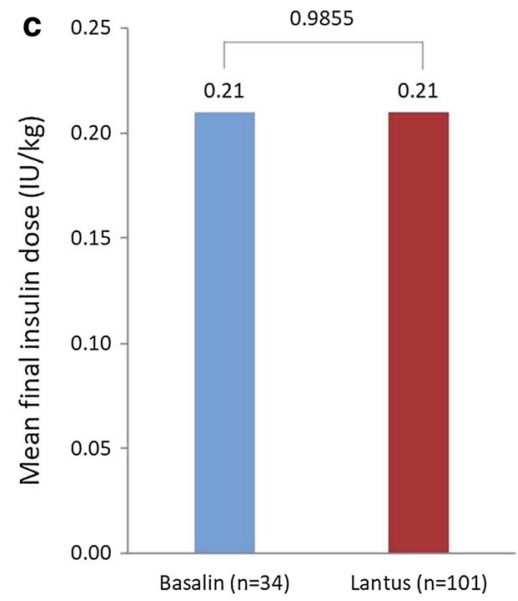

treated with Basalin or Lantus. $F B G$ fasting blood glucose, $I U$ international units, T2DM type 2 diabetes 


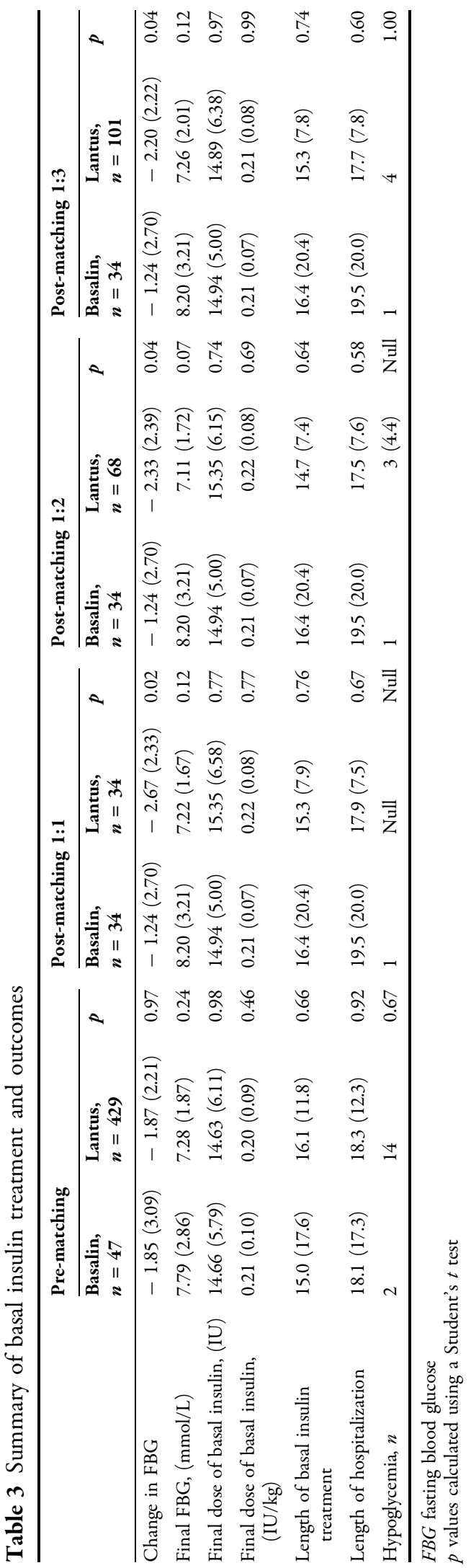

insulin glargine in hospitalized patients with diabetes. We found that the brand insulin glargine (Lantus) treatment was associated with greater reduction in mean FBG, at a similar final insulin dose and with a similarly low incidence of hypoglycemia, compared with the biosimilar insulin glargine (Basalin) in this propensity score matched retrospective analysis in noncritical hospitalized patients. In addition, patients who received Lantus also showed a trend towards greater reductions in post-breakfast and pre-lunch BG compared with those receiving Basalin, although these treatment differences did not reach statistical significance.

Hyperglycemia control was important for hospitalized patients. A previous randomized controlled trial had demonstrated that, among hospitalized patients, compared to a mean FBG of $8.5 \mathrm{mmol} / \mathrm{L}$ in the conventional-treatment group, the intensive-treatment group reduced FBG to $5.7 \mathrm{mmol} / \mathrm{L}$, resulting in a significant inhospital mortality reduction from $10.9 \%$ to $7.2 \%$ (absolute risk reduction, 3.7\%). Moreover, the lower FBG level was also associated with a $46 \%$ reduction of bloodstream infections and $41 \%$ reduction of acute renal failure requiring dialysis or hemofiltration [15]. A subsequent observational study also showed a J-curve association between blood glucose level and mortality risk, with the nadir roughly between 5 and $8 \mathrm{mmol} / \mathrm{L}$ [16]. All the results pointed out a clear goal for glycemic control in hospitalized patients, and implied that maintaining blood glucose levels as close to normal as possible would improve clinical outcomes. Therefore, the magnitude of the difference in FBG improvement between the Lantus and Basalin treatments in this analysis (absolute difference $0.96 \mathrm{mmol} / \mathrm{L}$ ) is clinically meaningful. Indeed, we observed that length of basal insulin treatment and length of hospital stay were numerically lower with Lantus treatment, although there were no statistically significant differences between the two treatments. This might be because the matched sample size is too small to detect a difference between the two treatments.

Hypoglycemia is strongly associated with adverse outcomes in non-critical hospitalized patients [8, 17]. To avoid the risk of hypoglycemia, current guidelines recommended a 
less stringent blood glucose goal (7.8-$10.0 \mathrm{mmol} / \mathrm{L}$ ) for hospitalized patients, and the goal range of $6.1-7.8 \mathrm{mmol} / \mathrm{L}$ was only recommended to selected patients at low risk of hypoglycemia [18]. In our hospital, each patient was assessed at admission to determine if his/ her condition was critical. Non-critical patients were then assigned to antihyperglycemia treatment, and accurate and frequent blood glucose measurements were performed to detect if any trend showing blood glucose levels dropped too low. In this analysis, only five out of 135 noncritical patients experienced hypoglycemia, and the incidence of hypoglycemia was comparable between two treatment $(p=1.00)$. No patient in either group experienced a severe hypoglycemic event.

Insulin glargine is a basal insulin widely used in diabetes management. Nowadays, more biosimilar insulin glargine came to market. However, insulin has a narrow therapeutic window and a need for accuracy of dosing to ensure an optimum balance between efficacy and safety [19]. Though biosimilar insulin glargine had shown bioequivalent profiles to originator insulin glargine [12], concerns were still raised about their clinical efficacy and additional adverse effects. It is therefore necessary to evaluate the similarity of clinical efficacy and safety of the biosimilar insulin glargine to brand insulin glargine. Such comparison data will provide more references for physicians in their clinical decision-making.

In this retrospective analysis, all non-critical hospitalized patients received similar antihyperglycemic treatment and targeted at the same glycemic range. Propensity score matching was conducted to minimized interferences on blood glucose results. On the basis of such background, we found that, compared to biosimilar insulin glargine, brand insulin glargine was associated with a higher FBG reduction without increased hypoglycemia risk at a similar final insulin dose. These results implied that biosimilar insulin glargine probably had lower potency than the originator insulins in a real clinical setting.

The limitations of this study include the short duration of treatment and the singlecenter setting. As patients prefer to choose premixed insulin because of its relatively lower price and convenience of injection, many patients with basal insulin-based regimens during hospitalization were switched to premixed insulin-based regimens several days before discharge. Therefore, the number of patients treated with basal insulin-based regimens was limited as lots of subjects were excluded as a result of insulin regimen switching. To make the comparison more valid, we employed the procedure of propensity score matching to control potential selection bias due to nonrandom treatment allocation and to minimize the effect of confounding factors, such as duration of diabetes, proportion of male patients, HbA1c and BG levels at admission, etc.

\section{CONCLUSIONS}

In real-life clinical practice, injection of the brand insulin glargine, Lantus, provided better fasting glycemic control compared to biosimilar insulin glargine, Basalin, without increased hypoglycemia risk at a similar insulin dose. Further investigation in a randomized controlled trial is required before changes to treatment practice can be advocated.

\section{ACKNOWLEDGEMENTS}

We thank the participants of the study.

Funding. No funding or sponsorship was received for this study or publication of this article. The article processing charges and open access fee were funded by the authors.

Authorship. All named authors meet the International Committee of Medical Journal Editors (ICMJE) criteria for authorship for this manuscript, take responsibility for the integrity of the work as a whole, and have given final approval to the version to be published.

Disclosures. Xia Hu, Lei Zhang, Chao Dong, Yanhu Dong, Jikang Jiang and Weiguo Gao have no conflicts of interest to declare. 
Compliance with Ethics Guidelines. The study was approved by the Qingdao Endocrine and Diabetes Hospital's ethical committee and all procedures were in accordance with the 1964 Helsinki declaration and its later amendments or comparable ethical standards. Informed consent was obtained from all individual participants included in the study.

Data Availability. The datasets generated and analyzed during the current study are not publicly available but are available from the corresponding author on reasonable request.

Open Access. This article is distributed under the terms of the Creative Commons Attribution-NonCommercial 4.0 International License (http://creativecommons.org/licenses/ by-nc/4.0/), which permits any noncommercial use, distribution, and reproduction in any medium, provided you give appropriate credit to the original author(s) and the source, provide a link to the Creative Commons license, and indicate if changes were made.

\section{REFERENCES}

1. Jiang HJ, Stryer D, Friedman B, Andrews R. Multiple hospitalizations for patients with diabetes. Diabetes Care. 2003;26(5):1421-6.

2. Moss SE, Klein R, Klein BE. Risk factors for hospitalization in people with diabetes. Arch Intern Med. 1999;159(17):2053-7.

3. Yang W, Zhao W, Xiao J, et al. Medical care and payment for diabetes in China: enormous threat and great opportunity. PLoS One. 2012;7(9):e39513.

4. Lin W, Chen C, Guan H, Du X, Li J. Hospitalization of elderly diabetic patients: characteristics, reasons for admission, and gender differences. BMC Geriatr. 2016;16:160.

5. Cromarty J, Parikh S, Lim WK, Acharya S, Jackson TJ. Effects of hospital-acquired conditions on length of stay for patients with diabetes. Intern Med J. 2014;44(11):1109-16.
Umpierrez GE, Isaacs SD, Bazargan N, You X, Thaler LM, Kitabchi AE. Hyperglycemia: an independent marker of in-hospital mortality in patients with undiagnosed diabetes. J Clin Endocrinol Metab. 2002;87(3):978-82.

7. Barba R, Marco J, Canora J, et al. Prolonged length of stay in hospitalized internal medicine patients. Eur J Intern Med. 2015;26(10):772-5.

8. Turchin A, Matheny ME, Shubina M, Scanlon JV, Greenwood B, Pendergrass ML. Hypoglycemia and clinical outcomes in patients with diabetes hospitalized in the general ward. Diabetes Care. 2009;32(7):1153-7.

9. Dalal MR, Kazemi M, Ye F, Xie L. Hypoglycemia after initiation of basal insulin in patients with type 2 diabetes in the United States: implications for treatment discontinuation and healthcare costs and utilization. Adv Ther. 2017;34(9):2083-92.

10. Dailey G, Strange P. Lower severe hypoglycemia risk: insulin glargine versus NPH insulin in type 2 diabetes. Am J Manag Care. 2008;14(1):25-30.

11. Tieu C, Lucas EJ, DePaola M, Rosman L, Alexander GC. Efficacy and safety of biosimilar insulins compared to their reference products: a systematic review. PLoS One. 2018;13(4):e0195012.

12. Cheng S, Lu J, Pan C-Y, et al. Studies of pharmacokinetic, pharmacodynamic properties and bioequivalence of recombinant insulin glargine injection in healthy man. Chin $J$ Diabetes. 2010;18(5):387-93.

13. Hu X, Zhang L, Dong Y, Dong C, Jiang J, Gao W. Switching from biosimilar (Basalin) to originator (Lantus) insulin glargine is effective in Chinese patients with diabetes mellitus: a retrospective chart review. F1000Res. 2018;7:477.

14. Dong Y, Gao W, Zhang L, et al. Patient characteristics related to metabolic disorders and chronic complications in type 2 diabetes mellitus patients hospitalized at the Qingdao Endocrine and Diabetes Hospital from 2006 to 2012 in China. Diabetes Vasc Dis Res. 2017;14(1):24-32.

15. van den Berghe G, Wouters P, Weekers F, et al. Intensive insulin therapy in critically ill patients. N Engl J Med. 2001;345(19):1359-67.

16. Bagshaw SM, Egi M, George C, Bellomo R, Australia New Zealand Intensive Care Society Database Management Committee. Early blood glucose control and mortality in critically ill patients in Australia. Crit Care Med. 2009;37(2):463-70. 
17. Kim Y, Rajan KB, Sims SA, Wroblewski KE, Reutrakul S. Impact of glycemic variability and hypoglycemia on adverse hospital outcomes in noncritically ill patients. Diabetes Res Clin Pract. 2014;103(3):437-43.

18. American Diabetes Association. Standards of Medical Care in Diabetes-2018. Diabetes Care. 2018;41(Suppl 1):S1-159.
19. Lamont T, Cousins D, Hillson R, Bischler A, Terblanche M. Safer administration of insulin: summary of a safety report from the National Patient Safety Agency. BMJ. 2010;341:c5269. 